\title{
Angiogenesis Inhibitor
}

National Cancer Institute

\section{Source}

National Cancer Institute. Angiogenesis Inhibitor. NCI Thesaurus. Code C1742.

An agent or endogenous substance that inhibits the formation of capillaries from existing blood vessels. In cancer therapy, angiogenesis inhibitors preferentially target the new blood vessels that tumors require for oxygen and nutrition, thereby inhibiting the growth and spread of these tumors. 